\title{
What is the better surgical treatment option for recurrent common bile duct stones?
}

\author{
Chi Young Park ${ }^{1, *}$, Sung Hoon Choi ${ }^{2, *}$, Chang-II Kwon', Jae Hee Cho ${ }^{3,4}$, Sung III Jang ${ }^{3}$, Tae Hoon Lee ${ }^{5}$, \\ Joung-Ho Han ${ }^{6}$, Seok Jeong ${ }^{7}$, Kwang Hyun $\mathrm{Ko}^{1}$ \\ ${ }^{1}$ Digestive Disease Center, CHA Bundang Medical Center, CHA University School of Medicine, Seongnam, Korea \\ ${ }^{2}$ Department of General Surgery, CHA Bundang Medical Center, CHA University School of Medicine, Seongnam, Korea \\ ${ }^{3}$ Department of Internal Medicine, Gangnam Severance Hospital, Yonsei University College of Medicine, Seoul, Korea \\ ${ }^{4}$ Department of Internal Medicine, Gachon Gil Hospital, Gachon University College of Medicine, Incheon, Korea \\ ${ }^{5}$ Department of Internal Medicine, Soonchunhyang University Cheonan Hospital, Soonchunhyang University College of Medicine, \\ Cheonan, Korea \\ ${ }^{6}$ Department of Internal Medicine, Chungbuk National University College of Medicine, Cheongju, Korea \\ ${ }^{7}$ Department of Internal Medicine, Inha University School of Medicine, Incheon, Korea
}

Purpose: Repeating endoscopic retrograde cholangiopancreatography (ERCP) in patients with recurrent common bile duct (CBD) stones is problematic in many ways. Choledochoduodenostomy (CDS) and choledochojejunostomy (CJS) are 2 surgical treatment options for recurrent CBD stones, and each has different advantages and disadvantages. The aim of this study was to compare the 2 surgical options in terms of the recurrence rate of CBD stones after surgical treatment.

Methods: This retrospective multicenter study included all patients who underwent surgical treatment due to recurrent CBD stones that were not effectively controlled by medical treatment and repeated ERCP between January 2006 and March 2015. We collected data from chart reviews and medical records. A recurrent CBD stone was defined as a stone found 6 months after the complete removal of a CBD stone by ERCP. Patients who underwent surgery for other reasons were excluded.

Results: A total of 27 patients were enrolled in this study. Six patients underwent CDS, and 21 patients underwent CJS for the rescue treatment of recurrent CBD stones. The median follow-up duration was $290(180-1,975)$ days in the CDS group and $1,474(180-6,560)$ days in the CJS group $(P=0.065)$. The postoperative complications were similar and tolerable in both groups (intestinal obstruction; 2 of 27, 7.4\%; 1 in each group). CBD stones recurred in 4 patients after CDS (4 of $6,66.7 \%$ ), and 3 patients after CJS ( 3 of $21,14.3 \%)(P=0.010)$.

Conclusion: CJS may be a better surgical option than CDS for preventing further stone recurrence in patients with recurrent CBD stones.

[Ann Surg Treat Res 2020;99(6):329-336]

Key Words: Choledochoduodenostomy, Choledochojejunostomy, Choledocholithiasis, Choledochostomy, Endoscopic retrograde cholangiopancreatography

Received June 1, 2020, Revised August 5, 2020,

Accepted August 25, 2020

\section{Corresponding Author: Chang-II Kwon}

Digestive Disease Center, CHA Bundang Medical Center, CHA University

School of Medicine, 59 Yatap-ro, Bundang-gu, Seongnam 13496, Korea

Tel: +82-31-780-5641, Fax: +82-31-780-5219

E-mail: endoscopy@cha.ac.kr

ORCID: https://orcid.org/0000-0003-3621-9023
*Chi Young Park and Sung Hoon Choi contributed equally to this study as co-first authors.

Copyright (C) 2020, the Korean Surgical Society

(c) Annals of Surgical Treatment and Research is an Open Access Journal. All articles are distributed under the terms of the Creative Commons Attribution NonCommercial License (http://creativecommons.org/licenses/by-nc/4.0/) which permits unrestricted non-commercial use, distribution, and reproduction in any medium, provided the original work is properly cited. 


\section{INTRODUCTION}

Common bile duct (CBD) stones are a major cause of acute cholangitis, and endoscopic stone removal using endoscopic retrograde cholangiopancreatography (ERCP) is widely used as the primary treatment option. A CBD stone found within 6 months after endoscopic stone removal is defined as a residual stone, and a CBD stone found after 6 months is defined as a recurrent stone. Recurrence within 6 months is not defined as a true $\mathrm{CBD}$ stone recurrence because it means that the $\mathrm{CBD}$ stone was not completely removed and remained after the previous attempt [1]. The recurrence of CBD stones after endoscopic biliary sphincterotomy has been reported in $4 \%-24 \%$ of the cases [2-7].

Because CBD stone recurrence can eventually lead to serious complications, such as recurrent cholangitis, hepatic abscess, biliary sepsis, and biliary cirrhosis, preventive methods are necessary for minimizing incomplete stone removal and stone recurrence. Therefore, to prevent CBD stone recurrence, it is important to identify and manage risk factors for CBD stones or diagnose and treat recurrent CBD stones early by regularly examining patients at high risk of recurrence.

Recurrent CBD stones are mostly pigmented gallstones that can be effectively and safely treated through ERCP procedures [8-11]. It is not known whether ursodeoxycholic acid (UDCA) is effective in preventing stone recurrence after successful removal. This is because data on the role of drug therapy after $\mathrm{CBD}$ stone removal are very limited, and the mechanism of pigmented stone formation, which accounts for the majority of recurrent CBD stones, is different from that of cholesterol gallstones [12]. Although performing a preventive ERCP every year could reduce further CBD stone recurrence in patients who have relapsed more than twice after CBD stone removal, it is not easy to apply the method in clinical practice [13]. Furthermore, it is not always easy to consider ERCP for patients who relapse more often than once a year as repeated recurrences can lead to serious complications and excessive medical expenses. Therefore, another treatment method should be identified.

Surgical treatment could be an alternative for patients with recurring CBD stones [14]. However, surgical treatment is a more complex and invasive method than ERCP, and should be reserved for selective patients at a high risk of recurrent biliary complications, such as those with irreversible severe dilatation of the CBD or other patients in whom ERCP fails [15]. There are 2 commonly used surgical procedures to treat recurrent CBD stones, choledochoduodenostomy (CDS) and choledochojejunostomy (CJS), including hepaticojejunostomy. The choice is mainly up to the surgeons, considering patient's factors and plans for accessing the CBD and preventing recurrence or complications. CDS has been preferred by many surgeons due to its anatomical advantages. It is easy to perform and permits easy access to ERCP procedures after surgery. However, CDS can cause sump syndrome and recurrent cholangitis due to reflux of the duodenal contents. CDS cannot correct CBD dilation, the biggest risk factor for CBD stone recurrence. Therefore, it is not the ultimate treatment in terms of CBD stone recurrence [5-7]. Otherwise, CJS is preferable in some cases of severe duodenal scarring and high-risk patients expected to develop postoperative complications $[16,17]$. Also, when CBD stones recur in patients who underwent CJS, an ERCP procedure is difficult due to the altered anatomy, so it is inevitably treated with a more invasive method, such as percutaneous transhepatic biliary drainage.

To determine which is ultimately the better surgical procedure for rescue therapy for recurrent $\mathrm{CBD}$ stones, the long-term $\mathrm{CBD}$ stone recurrence rate after surgery should be compared. The aim of this study was to compare the 2 surgical options in terms of CBD stone recurrence rates and related complications after surgery.

\section{METHODS}

\section{Patient recruitment}

Patients were retrospectively enrolled from 6 academic referral centers who underwent surgery due to recurrent CBD stones that were not effectively controlled by medical treatment and repeated ERCP between January 2006 and March 2015. A recurrent $\mathrm{CBD}$ stone was defined as a stone found 6 months after the complete removal of a CBD stone by ERCP. Patients who had a history of stomach surgery or underwent surgery for reasons other than recurrent CBD stones or combined malignancy were excluded. Patients who underwent surgery due to failed ERCP were also excluded. Patients with a surgical follow-up period less than 12 months were also excluded. This study was approved by the Institutional Review Board of CHA Medical Center (No. CHAMC 2020-04-074). As a retrospective medical record study, this study was conducted with exemption from informed consent.

\section{Data collection}

We collected data from chart reviews and medical records, including baseline characteristics, CBD stone recurrence rate, the interval from the initial CBD stone occurrence to surgery, the follow-up period after surgery, the last laboratory results, ERCP findings, CT findings before surgery, the types of CBD stones, coexisting biliary conditions (cholecystectomy status, cholelithiasis, periampullary diverticulum, CBD stricture, etc.), the type of surgery, and postoperative complications. The CBD diameter was measured by separating the proximal part and the distal part on axial CT images and the larger of the 2 values was chosen. The diameter immediately distal to the porta hepatis was measured for the proximal CBD, while the diameter visible 
in the head of the pancreas was measured for the distal CBD [18].

The primary outcome of this study was a comparison of 2 surgical options. The study also investigated differences in the clinical results, especially CBD stone recurrence, to explain the main reason for the differences.

\section{Statistical analysis}

The median and range were used to summarize the data for continuous variables and percentages for categorical variables. The continuous variables were analyzed using the MannWhitney U-test, and the categorical variables were analyzed using Pearson chi-squared test or Fisher exact test. Logistic regression analysis was also used to describe the data and explain the relationship between the variables. A P-value of $<0.05$ was considered significant. Statistical analyses were performed with IBM SPSS Statistics ver. 21.0.0 software (IBM Corp., Armonk, NY, USA).

\section{RESULTS}

\section{Baseline characteristics and clinical outcomes}

Table 1 shows the baseline characteristics and main clinical outcomes. Although we analyzed 10 years of data from 6 hospitals, a total of 27 patients were enrolled in this study. Six patients underwent CDS, and 21 patients underwent CJS. There were no differences in baseline characteristics and laboratory tests results between the 2 groups. Important factors, such as the $\mathrm{CBD}$ stone recurrence rate before surgery or maximal CBD diameter, were not statistically different between the 2 groups. Also, the type of CBD stones was all brown pigmented stones and the coexisting biliary conditions were not different between the 2 groups. However, it should be noted that periampullary diverticulum and cholecystectomy state, known as risk factors for recurrent CBD stones, were frequent in both groups.

The median follow-up period was 290 days (range, 185-1,975 days) in the CDS group and 1,474 days (range, 190-6,560 days) days in the CJS group $(P=0.065)$. Although the difference was not statistically significant, the difference was related to stone recurrence after surgical treatment. CBD stones recurred in 4 patients after CDS (4 of 6, 66.7\%) and 3 patients after CJS ( 3 of $21,14.3 \%)(P=0.010)$. The postoperative complications were similar and tolerable in both groups. Specifically, although intestinal obstruction occurred in 2 patients ( 2 of 27, 7.4\%; 1 in each group), all patients completely improved with conservative management. There was no mortality in either group.

Fig. 1 shows the most characteristic findings of a patient with CBD stone recurrence after CDS operations. A 78-yearold man underwent laparoscopic cholecystectomy due to symptomatic GB stones 9 years before undergoing CDS surgery. He was hospitalized multiple times due to acute cholangitis caused by multiple recurrent $\mathrm{CBD}$ stones, and received 5 ERCPs over 2 years prior to CDS surgery. Whenever CBD stones recur, life-threatening events, such as acute cholangitis, septic shock, and acute exacerbation of chronic kidney disease, were accompanied. Therefore, CDS surgery was performed as a rescue treatment for the recurrent $\mathrm{CBD}$ stones. There was no recurrence of $\mathrm{CBD}$ stones for 20 months after CDS surgery, but after that, the patient had 3 recurrences in 10 months. Eventually, CJS surgery was performed. The patient was

Table 1. Baseline characteristics and clinical outcomes

\begin{tabular}{|c|c|c|c|}
\hline Variable & Choledochoduodenostomy group $(n=6)$ & Choledochojejunostomy group $(n=21)$ & P-value \\
\hline Age (yr) & $80.5(65.0-92.0)$ & $76.0(51.0-99.0)$ & 0.550 \\
\hline Male sex & $5(83.3)$ & $11(52.4)$ & 0.029 \\
\hline CBD stone recurrence before surgery (time) & $5(3-8)$ & $5(4-14)$ & 0.974 \\
\hline Maximal CBD diameter $(\mathrm{mm})$ & $17.6(15.0-26.0)$ & $21.5(15.0-42.0)$ & 0.240 \\
\hline CBD stricture & $2(33.3)$ & $8(38.1)$ & $>0.999$ \\
\hline Periampullary diverticulum & $3(50.0)$ & $14(66.7)$ & 0.638 \\
\hline Cholecystectomy state & $4(66.7)$ & $15(71.4)$ & $>0.999$ \\
\hline Total bilirubin (mg/dL) & $1.2(0.2-5.8)$ & $1.6(0.3-17.8)$ & 0.569 \\
\hline AST (IU/L) & $42(17-172)$ & $63(16-517)$ & 0.659 \\
\hline ALT (IU/L) & $19(9-246)$ & $86(13-653)$ & 0.200 \\
\hline WBC $(/ \mu \mathrm{L})$ & $7,800(7,520-24,510)$ & $9,090(4,500-22,900)$ & 0.801 \\
\hline $\mathrm{CRP}(\mathrm{mg} / \mathrm{dL})$ & $19.0(0.44-68.0)$ & $3.2(0.03-27.93)$ & 0.296 \\
\hline Albumin (g/dL) & $4.0(2.3-4.3)$ & $3.7(2.3-4.9)$ & 0.801 \\
\hline$\gamma-\mathrm{GTP}(\mathrm{U} / \mathrm{L})$ & $48(9-382)$ & $191(10-739)$ & 0.509 \\
\hline $\operatorname{ALP}(I U / L)$ & $190(96-1,706)$ & $266(45-2,512)$ & 0.705 \\
\hline Follow-up period after surgery (day) & $290(185-1,975)$ & $1,474(190-6,560)$ & 0.065 \\
\hline CBD stone recurrence after surgery (time) & $4(66.7)$ & $3(14.3)$ & 0.010 \\
\hline
\end{tabular}

Values are presented as median (range) or number (\%).

CBD, common bile duct. 

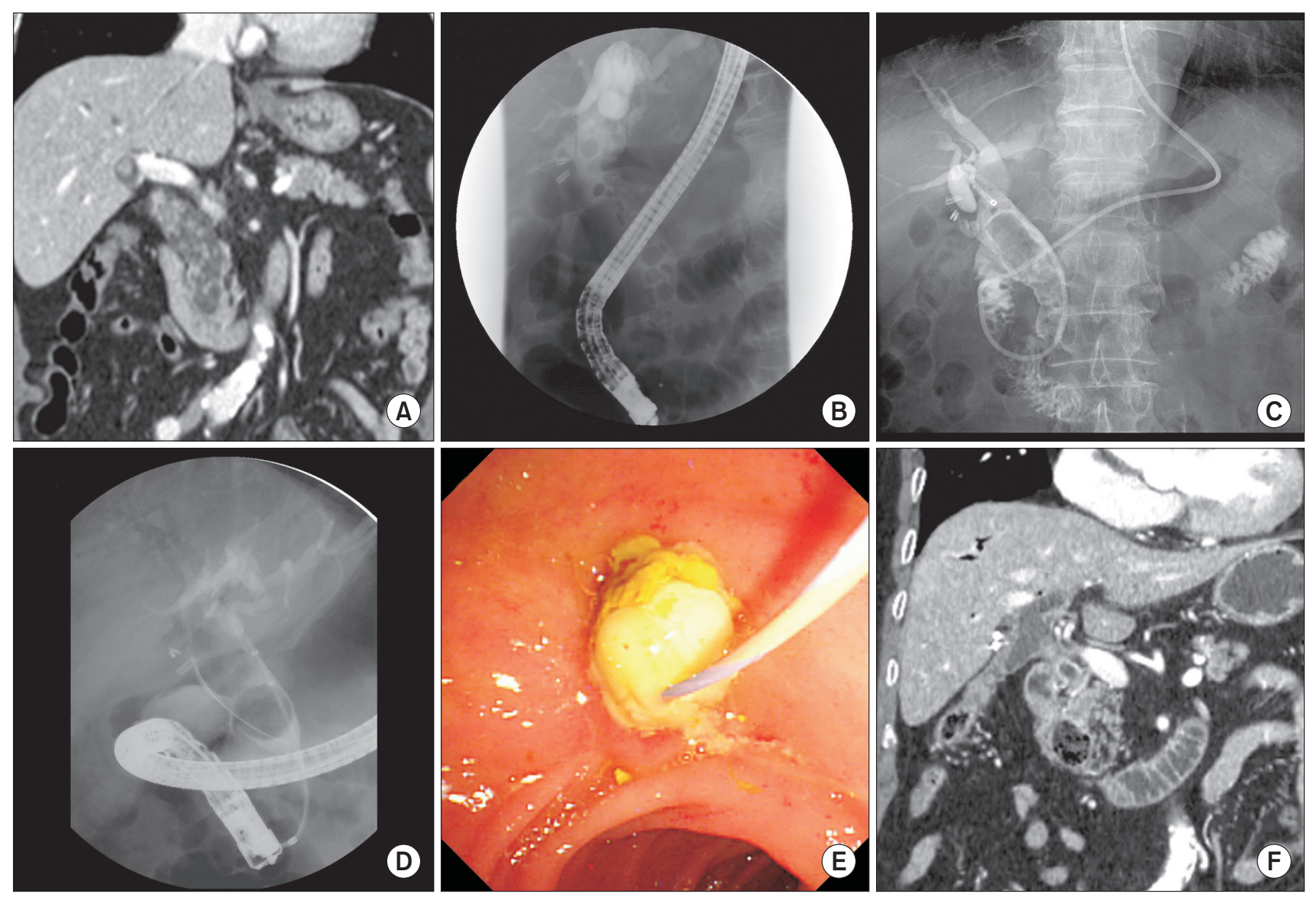

Fig. 1. (A) CT findings at the first visit. Heterogeneous material fills in the dilated common bile duct (CBD). (B) Cholangiography findings by endoscopic retrograde cholangiopancreatography at the first visit. Numerous and various sized round filling defects in the dilated CBD. (C) Findings from a cholangiography performed through a nasobiliary drainage tube at the third recurrence. Unlike the first attack, larger filling defects are impacted within the dilated CBD. (D) Cholangiography findings at the first recurrence of $\mathrm{CBD}$ stones after choledochoduodenostomy (CDS). As with previous recurrence findings, large filling defects are impacted within the dilated CBD. (E) Endoscopic findings at the third recurrence of CBD stones after CDS. Whitish pus is drained from the CDS site. (F) The last CT findings at 48 months after choledochojejunostomy (CJS). Stone recurrence is not observed in the remaining proximal CBD and CJS areas.

Table 2. Univariate analysis of factors associated with common bile duct (CBD) stone recurrence after surgery

\begin{tabular}{|c|c|c|c|c|c|}
\hline Variable & $\begin{array}{c}\text { Recurred } \\
\text { patient }(n=7)\end{array}$ & $\begin{array}{l}\text { Non-recurred } \\
\text { patient }(n=20)\end{array}$ & $\begin{array}{l}\text { Odds } \\
\text { ratio }\end{array}$ & $95 \% \mathrm{Cl}$ & P-value \\
\hline Age $(y r)$ & $69.0(58-82)$ & $80.5(51-99)$ & 0.942 & $0.869-1.020$ & 0.138 \\
\hline Male sex & $4(25.0)$ & $12(75.0)$ & 0.889 & $0.155-5.084$ & 0.895 \\
\hline CBD stone recurrence before surgery (time) & $4(3-8)$ & $5(4-14)$ & 0.679 & $0.430-1.356$ & 0.358 \\
\hline Maximal CBD diameter $(\mathrm{mm})$ & $18.8(15.0-27.0)$ & $21.5(15.0-42.0)$ & 0.924 & $0.771-1.107$ & 0.390 \\
\hline Total bilirubin (mg/dL) & $1.1(0.2-15.5)$ & $1.7(0.3-17.8)$ & 1.003 & $0.817-1.232$ & 0.974 \\
\hline AST (IU/L) & $43(34-172)$ & $76(16-517)$ & 0.994 & $0.981-1.006$ & 0.331 \\
\hline ALT (IU/L) & $39.5(16-246)$ & $86(9-653)$ & 0.998 & $0.989-1.007$ & 0.618 \\
\hline WBC $(/ \mu \mathrm{L})$ & $9,000(5,080-13,640)$ & $8,595(4,500-24,510)$ & 1.000 & $1.000-1.000$ & 0.362 \\
\hline $\mathrm{CRP}(\mathrm{mg} / \mathrm{dL})$ & $20.41(0.4-68)$ & $3.17(0.03-19.0)$ & 1.101 & $0.968-1.252$ & 0.143 \\
\hline Albumin (g/dL) & $4.1(2.4-4.3)$ & $3.6(2.3-4.9)$ & 1.567 & $0.445-5.518$ & 0.484 \\
\hline$\gamma-\mathrm{GTP}(\mathrm{U} / \mathrm{L})$ & $349(33-382)$ & $167(9-739)$ & 0.999 & $0.994-1.004$ & 0.694 \\
\hline $\operatorname{ALP}(I U / L)$ & $245(83-328)$ & $277.5(45-2,512)$ & 0.997 & $0.991-1.003$ & 0.255 \\
\hline Choledochoduodenostomy:choledochojejunostomy & $4: 3$ & $2: 18$ & 12.0 & $1.482-97.179$ & 0.020 \\
\hline
\end{tabular}

Values are presented as median (range), number (\%), or number only. 
undergoing regular outpatient follow-up without recurrence of CBD stones for 43 months since the CJS surgery. We believe that the inability to correct a $\mathrm{CBD}$ dilation up to $26 \mathrm{~mm}$ had the greatest impact on persistent CBD stone recurrence.

\section{Factors associated with CBD stone recurrence after surgery \\ Table 2 shows the factors associated with CBD stone} recurrence after surgery. The surgical method was the only factor associated with CBD stone recurrence after surgery. CDS was more closely associated with stone recurrence after surgery than CJS (odds ratio [OR], 12.0; $\mathrm{P}=0.020$ ). Importantly, CBD diameter, associated with stone recurrence after ERCP, was not correlated with stone recurrence after surgical treatment $(\mathrm{P}=0.390)$. Coexisting biliary conditions (CBD stricture, periampullary diverticulum and cholecystectomy state) were excluded from the analysis due to anatomical changes after surgery.

\section{DISCUSSION}

For endoscopists who perform ERCP, close cooperation with surgeons is critical in determining the best treatment of patients with pancreato-biliary disease. In general, it is common to have a surgical referral to perform a cholecystectomy in patients with coexisting gallbladder stones or cholecystitis. In addition, if ERCP with stone removal fails, if accompanying biliary conditions need to be corrected at the same time, or if $\mathrm{CBD}$ stones recur too often, a surgical referral may be considered. As mentioned earlier, recurrent CBD stones are generally treated by an ERCP procedure, which allows patients to return to their daily routine without any problems. When the type of recurrent CBD stone is a brown pigmented stone and that is not hard and consisting of multiple stones, the ERCP procedure is not difficult and does not require a high degree of expertise [8-11]. However, if CBD stones recur too often in elderly patients, this can be accompanied by recurrent cholangitis, hepatic abscess, and biliary sepsis, which may be life-threatening. Moreover, repeated hospitalizations mean increased medical expenses, and this factor should not be ignored. Therefore, to ultimately solve this difficult situation, we must consult a surgeon $[14,15]$.

However, ERCP endoscopists usually worry about CBD stone recurrence after surgical treatment. Because surgical treatment is not an ultimate treatment method to remove all risks of $\mathrm{CBD}$ stone recurrence, the potential for recurrence cannot be ignored. The CDS method has the disadvantage of not usually correcting a dilated $\mathrm{CBD}$, but the advantage of being able to perform another ERCP procedure when the CBD stone recurs is attractive. In contrast, the CJS method can be expected to prevent $\mathrm{CBD}$ stone recurrence because it corrects dilated CBDs to some extent. However, if stones recur, an ERCP procedure is generally impossible, putting medical staff in a difficult position.

Whether CDS or CJS is the best treatment for CBD stones has been discussed for a long time. Long ago, CJS was associated with higher operative mortality and procedurerelated complications than CDS. Thus, CDS was recommended more often [17]. A multicenter prospective randomized trial was performed by a French surgical research group [19]. They evaluated age, CBD diameter, operative time, and stone recurrence. Although the CBD was markedly dilated (mean CBD diameter, $18.22 \pm 4.01 \mathrm{~mm}$ ), the study found no difference in long-term outcomes between patients who underwent $\mathrm{CDS}$ and those who underwent CJS. They recommended and concluded that CDS was preferable for CBD stone for 2 reasons. First, CDS is technically easier and faster to perform than CJS. Second, unlike CJS, CDS permits easy access to further endoscopic treatment if necessary. However, the study was designed to compare both surgical methods for all CBD stone patients, not just for patient with frequent recurrences. A Chinese group reported the recurrence of $\mathrm{CBD}$ stones after surgical treatment in elderly patients [20]. They compared 3 surgical modalities, choledocholithotomy with T-tube drainage group, a CDS group, and a CJS group. They concluded by recommending CDS for elderly patients with primary CBD stones to prevent postoperative recurrent $\mathrm{CBD}$ stones. However, they enrolled only elderly patients over 70 years of age, and older patients are more likely to have complications from surgery. The authors also mentioned that CJS was a more technically difficult method than CDS.

It is difficult to find research that refutes this statement, but clues can be found in the reports of studies on the occlusion of plastic stents [21-23]. They suggested that duodeno-biliary reflux and bile turbulence plays an important role in stent occlusion. Therefore, CBD stone formation might be likely to occur in CDS patients with dilated CBDs. Also, since a dilated CBD is an important factor in CBD stone formation from bile turbulence, the risk of $\mathrm{CBD}$ stone recurrence would be corrected because CJS or hepaticojejunostomy usually correct dilated CBDs to some extent.

Because of the limited number of studies, we were unable to provide an objective answer to the patient's preoperative question, "Doesn't the CBD stone recur again?" We wanted to be convinced that although the CJS method alters the anatomy, if it effectively prevents stone recurrence, then a patient rarely needs retreatment after surgery.

Our study showed that CJS was a more reasonable surgical method to prevent stone recurrence after surgery in patients with recurrent CBD stones. Although CJS is technically a more difficult surgical procedure, there was no significant difference in surgical complications due to refinement in surgeons' techniques and advancements in surgical instruments. Unlike 
past reports, the postoperative complications were tolerable, and there was no mortality in our patients.

As we previously mentioned, comparative studies of the prevalence of cholangitis or CBD stones according to the method of enterobiliary reconstruction are sparse. There are some reports showing no significant difference in the long-term outcome of CDS or CJS after choledochal cyst excisions [24,25]. However, several studies with a different research objective favored CDS because of the lower incidence of duodenogastric reflux [26-28]. Although CDS seems more physiological biliary drainage, Shimotakahara et al. [29] reported a higher rate of endoscopy-proven duodenogastric reflux in a CDS group compared to a CJS group (33.3\% vs. 0\%). Hamada et al. [30] also showed that all 17 patients who underwent CDS had duodenogastric bile reflux in endoscopic examination, and 14 of the 17 patients presented abdominal symptoms, and 7 patients underwent CJS conversion surgery for intractable abdominal pain. These studies indicate that CJS might be more reasonable for biliary-enteric continuity compared to CDS.

The important points in the baseline characteristics (Table 1) were that $\mathrm{CBD}$ stones recurred an average of 5 times in both groups, and the CBD diameter was a median of $17.6 \mathrm{~mm}$ (range, $15-26 \mathrm{~mm}$ ) in the CDS group, and $21.5 \mathrm{~mm}$ (range, 15-42 $\mathrm{mm}$ ) in the CJS group. In addition to the above 2 risk factors for CBD stone recurrence, periampullary diverticulum was present in more than $50 \%$ of the patients in both groups, and a cholecystectomy state was present in more than two-thirds of both groups. The median follow-up period was statistically insignificant between the 2 groups, but shorter in the CDS group. The difference was related to the stone recurrence after surgical treatment. Because CBD stones found within 6 months after surgery were excluded from the results because these patients did not meet the enrollment criteria, that was an overlooked part of this study. CBD stones may recur early due to postoperative complications after surgery. At the time of surgery, a residual CBD stone can be confirmed, so it is difficult to determine whether CBD stones found within 6 months are residual CBD stones. If this had been further confirmed, the results could have been more conclusive.

The main result of this study was that the recurrence of CBD stones after surgery was significantly different between the 2 groups; 4 of 6 patients $(66.7 \%)$ in the CDS group vs. 3 of 21 patients $(14.3 \%)$ in the CJS group $(\mathrm{P}=0.010)$. Although the number of patients in the CDS group was small, the difference between the 2 groups was confirmed by a nonparametric statistical method. CDS was highly associated with stone recurrence than CJS (OR, 12.0; $\mathrm{P}=0.020)$. As mentioned earlier, this result can be an important basis for recommending surgery to patients. In addition, considering the period of follow-up after surgery, the average recurrence rate may be $15 \%$ during 10 years after CJS surgery. In contrast, the average recurrence rate may be more than $50 \%$ during a relatively shorter period after CDS surgery. Therefore, from the perspective of CBD stone recurrence, it may be desirable to recommend CJS over CDS. Contrary to the results of previous studies, the risk factors of recurrent $\mathrm{CBD}$ stone before surgery (e.g., dilated CBD, periampullary diverticulum, CBD angulation, and CBD stricture, etc.) may be corrected after CJS. To accurately prove this, a largescale prospective study would be required but might be difficult to accomplish due to the quite small number of patients.

The limitations of this study are as follows: (1) This study was a retrospective multicenter study and the patients were not properly randomized; (2) patients with recurrent CBD stones are rarely operated on, so the sample size was quite small. The data were collected from 6 academic referral centers for 10 years, but only 27 patients were enrolled; (3) the number of patients in the 2 groups was quite different, and since there were only 6 patients in CDS group, there may be a big problem in interpreting the results. Therefore, nonparametric statistical methods were used for analyzing the results; (4) because the surgical treatments were performed at 6 different hospitals, differences in surgical skills and equipment could have influenced the results of the study; and (5) UDCA was administered to all included patients, but whether the patients continued to take it was a limitation of the retrospective study. Despite these limitations, we believe that our study is important because it provides important information to clinicians. This study reviewed the results of 2 surgical options and provided some important information about related problems.

In conclusion, this retrospective multicenter study revealed that CDS may be more related to stone recurrence after surgery in patients with recurrent CBD stones. Therefore, CJS may be a better surgical option than CDS for preventing stone recurrence in patients with recurrent CBD stones. We believe that our results will serve as a basis for establishing treatment policies in that situation. A prospective, randomized, and controlled multicenter study would further identify the superiority between the 2 surgical options.

\section{ACKNOWLEDGEMENTS}

\section{Conflict of Interest}

No potential conflict of interest relevant to this article was reported.

\section{ORCID iD}

Chi Young Park: https://orcid.org/0000-0002-9938-2955

Sung Hoon Choi: https://orcid.org/0000-0002-1664-3727

Chang-Il Kwon: https://orcid.org/0000-0003-3621-9023

Jae Hee Cho: https://orcid.org/0000-0003-4174-0091

Sung Ill Jang: https://orcid.org/0000-0003-4937-6167 
Tae Hoon Lee: https://orcid.org/0000-0002-3545-9183

Joung-Ho Han: https://orcid.org/0000-0003-4469-9215

Seok Jeong: https://orcid.org/0000-0001-6178-8338

Kwang Hyun Ko: https://orcid.org/0000-0001-5168-1377

Author Contribution

Conceptualization: CIK
Formal Analysis: CYP, JHC, SIJ, THL, JHH, SJ

Investigation: CYP, JHC, SIJ, THL, JHH, SJ

Methodology: CIK, SHC, KHK

Project Administration: CIK

Writing - Original Draft: CYP, CIK

Writing - Review \& Editing: SHC, JHC, SIJ, THL, JHH, SJ, KHK

\section{REFERENCES}

1. Keizman D, Shalom MI, Konikoff FM. An angulated common bile duct predisposes to recurrent symptomatic bile duct stones after endoscopic stone extraction. Surg Endosc 2006;20:1594-9.

2. Freeman ML, Nelson DB, Sherman S, Haber GB, Herman ME, Dorsher PJ, et al. Complications of endoscopic biliary sphincterotomy. N Engl J Med 1996;335: 909-18.

3. Hawes RH, Cotton PB, Vallon AG. Followup 6 to 11 years after duodenoscopic sphincterotomy for stones in patients with prior cholecystectomy. Gastroenterology 1990;98:1008-12.

4. Prat F, Malak NA, Pelletier G, Buffet C, Fritsch J, Choury AD, et al. Biliary symptoms and complications more than 8 years after endoscopic sphincterotomy for choledocholithiasis. Gastroenterology 1996;110:894-9.

5. Ando T, Tsuyuguchi T, Okugawa T, Saito M, Ishihara T, Yamaguchi T, et al. Risk factors for recurrent bile duct stones after endoscopic papillotomy. Gut 2003:52:11621.

6. Pereira-Lima JC, Jakobs R, Winter UH, Benz C, Martin WR, Adamek HE, et al. Longterm results ( 7 to 10 years) of endoscopic papillotomy for choledocholithiasis. Multivariate analysis of prognostic factors for the recurrence of biliary symptoms. Gastrointest Endosc 1998:48:457-64.

7. Costamagna G, Tringali A, Shah SK, Mutignani M, Zuccalà G, Perri V. Long-term follow-up of patients after endoscopic sphincterotomy for choledocholithiasis, and risk factors for recurrence. Endoscopy 2002;34:273-9.

8. Lai KH, Peng NJ, Lo GH, Cheng JS, Huang $\mathrm{RL}$, Lin CK, et al. Prediction of recurrent choledocholithiasis by quantitative cholescintigraphy in patients after endoscopic sphincterotomy. Gut 1997:41:399-403.

9. Cetta F. The role of bacteria in pigment gallstone disease. Ann Surg 1991;213:31526.

10. Bowser L, Schutz SM. The role of surveillance endoscopic retrograde cholangiopancreatography in preventing episodic cholangitis in patients with recurrent common bile duct stones. Gastrointest Endosc 2000;51:247-8.

11. Sugiyama M, Suzuki Y, Abe N, Masaki T, Mori T, Atomi Y. Endoscopic retreatment of recurrent choledocholithiasis after sphincterotomy. Gut 2004:53:1856-9.

12. Williams EJ, Green J, Beckingham I, Parks R, Martin D, Lombard M, et al. Guidelines on the management of common bile duct stones (CBDS). Gut 2008;57:1004-21.

13. Geenen DJ, Geenen JE, Jafri FM, Hogan WJ, Catalano MF, Johnson GK, et al. The role of surveillance endoscopic retrograde cholangiopancreatography in preventing episodic cholangitis in patients with recurrent common bile duct stones. Endoscopy 1998;30:18-20.

14. Kummerow KL, Shelton J, Phillips S, Holzman MD, Nealon W, Beck W, et al. Predicting complicated choledocholithiasis. J Surg Res 2012;177:70-4.

15. Uchiyama K, Onishi H, Tani M, Kinoshita H, Kawai M, Ueno M, et al. Long-term prognosis after treatment of patients with choledocholithiasis. Ann Surg
2003;238:97-102.

16. Matsushima K, Soybel DI. Operative management of recurrent choledocholithiasis. J Gastrointest Surg 2012;16:2312-7.

17. Blankensteijn JD, Terpstra OT. Early and late results following choledochoduodenostomy and choledochojejunostomy. HPB Surg 1990;2:151-8.

18. Yoon H, Kwon CI, Jeong S, Lee TH, Han $\mathrm{JH}$, Song TJ, et al. Clinical significance of biliary dilatation and cholelithiasis after subtotal gastrectomy. Korean J Gastroenterol 2015:66:33-40.

19. Panis Y, Fagniez PL, Brisset D, Lacaine F, Levard H, Hay JM. Long term results of choledochoduodenostomy versus choledochojejunostomy for choledocholithiasis. The French Association for Surgical Research. Surg Gynecol Obstet 1993;177:337.

20. Li ZF, Chen XP. Recurrent lithiasis after surgical treatment of elderly patients with choledocholithiasis. Hepatobiliary Pancreat Dis Int 2007;6:67-71.

21. Groen AK, Out T, Huibregtse K, Delzenne B, Hoek FJ, Tytgat GN. Characterization of the content of occluded biliary endoprostheses. Endoscopy 1987;19:57-9.

22. Weickert U, Venzke T, König J, Janssen J, Remberger K, Greiner L. Why do bilioduodenal plastic stents become occluded? A clinical and pathological investigation on 100 consecutive patients. Endoscopy 2001:33:786-90.

23. Kwon CI, Gromski MA, Sherman S, Easler JJ, El Hajj II, Watkins J, et al. Time sequence evaluation of biliary stent occlusion by dissection analysis of 
retrieved stents. Dig Dis Sci 2016;61:242635.

24. Narayanan SK, Chen Y, Narasimhan KL, Cohen RC. Hepaticoduodenostomy versus hepaticojejunostomy after resection of choledochal cyst: a systematic review and meta-analysis. J Pediatr Surg 2013;48: 2336-42.

25. Patil V, Kanetkar V, Talpallikar MC. Hepaticoduodenostomy for biliary reconstruction after surgical resection of choledochal cyst: a 25-year experience. Indian J Surg 2015;77:240-4.

26. Takada K, Hamada Y, Watanabe K, Tanano A, Tokuhara K, Kamiyama
Y. Duodenogastric reflux following biliary reconstruction after excision of choledochal cyst. Pediatr Surg Int 2005; 21:1-4.

27. Santore MT, Behar BJ, Blinman TA, Doolin EJ, Hedrick HL, Mattei P, et al. Hepaticoduodenostomy vs hepaticojejunostomy for reconstruction after resection of choledochal cyst. J Pediatr Surg 2011:46:209-13.

28. Mukhopadhyay B, Shukla RM, Mukhopadhyay M, Mandal KC, Mukherjee PP, Roy D, et al. Choledochal cyst: a review of 79 cases and the role of hepaticodochoduodenostomy. J Indian Assoc Pediatr Surg
2011;16:54-7.

29. Shimotakahara A, Yamataka A, Yanai T, Kobayashi H, Okazaki T, Lane GJ, et al. Roux-en-Y hepaticojejunostomy or hepaticoduodenostomy for biliary reconstruction during the surgical treatment of choledochal cyst: which is better? Pediatr Surg Int 2005;21:5-7.

30. Hamada Y, Hamada H, Shirai T, Nakamura Y, Sakaguchi T, Yanagimoto $\mathrm{H}$, et al. Duodenogastric regurgitation in hepaticoduodenostomy after excision of congenital biliary dilatation (choledochal cyst). J Pediatr Surg 2017;52:1621-4. 